University of Nebraska - Lincoln

DigitalCommons@University of Nebraska - Lincoln

U.S. Department of Veterans Affairs Staff

Publications

U.S. Department of Veterans Affairs

2011

How do clinical trial participants compare to other patients with schizophrenia?

Paul G. Barnett

VA Palo Alto Health Care System, paul.barnett@va.gov

Jennifer Y. Scott

VA Palo Alto Health Care System, jennifer.scott3@va.gov

Robert A. Rosenheck

Yale School of Medicine, robert.rosenheck@yale.edu

Follow this and additional works at: https://digitalcommons.unl.edu/veterans

Barnett, Paul G.; Scott, Jennifer Y.; and Rosenheck, Robert A., "How do clinical trial participants compare to other patients with schizophrenia?" (2011). U.S. Department of Veterans Affairs Staff Publications. 26. https://digitalcommons.unl.edu/veterans/26

This Article is brought to you for free and open access by the U.S. Department of Veterans Affairs at DigitalCommons@University of Nebraska - Lincoln. It has been accepted for inclusion in U.S. Department of Veterans Affairs Staff Publications by an authorized administrator of DigitalCommons@University of Nebraska - Lincoln. 


\title{
How do clinical trial participants compare to other patients with schizophrenia?
}

\author{
Paul G. Barnett ${ }^{\mathrm{a}, \mathrm{b}, *}$, Jennifer Y. Scott ${ }^{\mathrm{a}}$, Robert A. Rosenheck ${ }^{\mathrm{c}, \mathrm{d}}$ \\ and for the CSP 555 Study Group \\ ${ }^{a}$ Health Economics Resource Center (HERC), VA Cooperative Studies Program, VA Palo Alto Health Care System, 795 Willow Road (152), Menlo Park, CA 94025 USA \\ ${ }^{\mathrm{b}}$ Dept. of Health Research E' Policy, Stanford University Medical School, Palo Alto, CA USA \\ c Veterans Affairs Connecticut Health Care System, West Haven, CT, USA \\ d Yale School of Medicine, New Haven, CT, USA
}

\section{A R T I C L E I N F O}

Article history:

Received 30 November 2010

Received in revised form 26 March 2011

Accepted 29 March 2011

Available online 22 April 2011

\section{Keywords:}

Adherence

Cost

Anti-psychotic medication

Schizophrenia

\begin{abstract}
A B S T R A C T
Objective: Patients with schizophrenia enrolled in a trial of long-acting injectable risperidone at multiple sites of the Veterans Health Administration (VHA). We considered if the trial participants were representative of the targeted group of high-utilization patients with poor adherence to anti-psychotics.

Methods: Participants' characteristics, health services utilization, and cost in the year prior to randomization were compared to a randomly selected time-matched cohort of 10,000 other patients with schizophrenia who were not in the trial.

Results: There were few differences in the characteristics, utilization, or cost between trial participants and non-participants who met the key trial inclusion criterion of a history of psychiatric hospitalization in the prior 24 months. Trial participants were more likely to be African-American (45.5\% vs. $35.1 \%, \mathrm{p}<.001)$ and were less likely to have had a medical-surgical hospitalization in the study year ( $8.2 \%$ vs. $19.2 \% \mathrm{p}<.001$ ). Compared to non-participants who did not meet the inclusion criterion, trial participants were more likely to have a psychiatric condition in addition to schizophrenia ( $81.0 \%$ vs. $51.3 \%, \mathrm{p}<.001$ ), more likely to have a substance abuse disorder ( $46.3 \%$ vs. $13.9 \% \mathrm{p}<.001)$, and less likely to be adherent with their anti-psychotic medication (21.3\% vs. $37.9 \%, \mathrm{p}<.001)$. They also incurred more than three times the annual cost $(\$ 42,563 \mathrm{vs}$. $\$ 12,270, \mathrm{p}<.001)$.

Conclusions: Trial participants appeared to be representative of the $23.3 \%$ of VHA patients with schizophrenia who met the key trial inclusion criterion, suggesting that trial findings will be relevant to the broader group of high risk patients.
\end{abstract}

Published by Elsevier B.V.

\section{Introduction}

Lack of adherence with anti-psychotic medications is the most common cause of poor control of schizophrenia and higher health care costs, largely attributable to greater rates of psychiatric hospitalization (Weiden and Olfson, 1995; Thieda et al., 2003). The promise of better compliance and reduced hospitalization has resulted in the replacement of conventional anti-psychotic medications by second generation drugs. Long-acting injectable (LAI) formulations of second generation drugs have been developed with the goals of sustained medication levels in the blood, improved compliance and outcomes, and reduced hospitalization.

LAI risperidone (Risperdal ${ }^{\circledR}$ Consta ${ }^{\circledR}$ ) is the first LAI formulation of a second generation anti-psychotic to become available. Some

\footnotetext{
* Corresponding author at: Health Economics Resource Center (HERC), VA Cooperative Studies Program, VA Palo Alto Health Care System, 795 Willow Road (152), Menlo Park, CA 94025 USA. Tel.: + 1650493 500x22475; fax: + 16506172639.

E-mail addresses: paul.barnett@va.gov (P.G. Barnett), jennifer.scott3@va.gov (J.Y. Scott), robert.rosenheck@yale.edu (R.A. Rosenheck).
}

economic models have estimated that the substantial cost of this drug may be offset by reductions in the cost of hospitalization (Chue et al., 2005b; Edwards et al., 2005; Yang et al., 2005).

This medication has been compared to placebo in a randomized trial (Kane et al., 2003). Observational studies have found that switching from other anti-psychotic medications to LAI risperidone is associated with improved outcomes and reduced hospitalization (Fleischhacker et al., 2003; Lindenmayer et al., 2004; Moller et al., 2005) but these studies have involved stable patients and did not include a control group. Three randomized trials also involving stable patients have thus far shown no advantage for LAI risperidone therapy (Chue et al., 2005a; Bai et al., 2007; Keks et al., 2007). A review of clinical trials of schizophrenia care found that study participants often differ from the average patient (Gilbody et al., 2002). Trials of antipsychotic medications that include unrepresentative patients have limited relevance and the trend has been towards effectiveness trials designed to resemble normal practice (Johnsen and Jorgensen, 2008).

The U.S. Veterans Health Administration (VHA) completed enrollment of patients in a randomized trial comparing LAI risperidone to the psychiatrist's choice of oral antipsychotic therapy in 
unstable schizophrenia. Because unstable patients have frequent psychiatric hospital stays, they might benefit the most from a longacting medication, and they represent the group in which the hypothesis of cost offset is most likely to prove true.

A key inclusion criterion to identify unstable patients was a history of psychiatric hospitalization in the prior 24 months. We wished to determine if this criterion succeeded in selecting from VHA patients diagnosed with schizophrenia those who had the poorest medication adherence and highest VHA health care cost. We evaluated the potential relevance of this practical clinical trial to general VA clinical practice by find the proportion of patients who met the trial inclusion criterion and determining if trial participants were typical of patients who met this criterion.

To answer these questions, we compared the utilization and cost of trial participants in the year prior to randomization to a time-matched cohort of 10,000 other VHA patients diagnosed with schizophrenia who were not in the trial.

\section{Materials and methods}

\subsection{Clinical trial cohort}

A randomized clinical trial compared bi-weekly administration of 25-50 mg of LAI risperidone to the psychiatrist's choice of oral antipsychotic medication. The trial enrolled patients receiving care in the Veterans Health Administration (VHA) for treatment of schizophrenia or schizo-affective disorder. Patients were included if they had a psychiatric hospitalization in the previous 2 years or were judged to be at risk of hospitalization because of increasing recent psychiatric service use. Almost all (95\%) of trial participants had history of hospitalization within the prior 2 years. Patients provided informed consent under a human subjects protocol at each trial site.

This paper compares service use, cost, and medication adherence among participants in the year prior to randomization to a cohort of 10,000 users of VHA health care diagnosed with schizophrenia or schizoaffective disorder. Trial participants were enrolled between September 2006 and December 2008. The comparison cohort was time-matched to trial enrollment comparison so that any secular trends in patterns of service delivery would have the same effect on both groups.

\subsection{Comparison cohort}

We created a list of all users of VHA who had at least one visit or hospital stay with a diagnosis of schizophrenia or schizoaffective disorder (ICD-9 codes beginning with the digits 295) during the years of trial enrollment. After excluding trial participants, this list included 124,108 unique individuals. For each year of trial enrollment, we sampled without replacement individuals who did not participate in the trial who had received VHA care in that year, using a quota that maintained the proportional distribution over time of trial enrollment. A total of 10,000 individuals was selected for study. They represented $8.1 \%$ of the VA patient population diagnosed with schizophrenia during the period of trial enrollment. Use of these patients' data was approved by the human subjects' review committee of Stanford University.

Each member of the non-participant comparison group was studied for one year. A study period was defined for each of the three years in which non-participants were selected. To maintain time-matching with the observations for trial participants, year-long periods were defined to end on the mean value of the randomization date of the trial participants who enrolled in that year.

We applied the trial inclusion criterion to non-participants by assessing if they had an acute VA psychiatric hospitalization in the prior 24 months. We did not have information on their use of non-VA psychiatric hospitals. We determined which of the non-participants who met inclusion criterion also received most of their care at a site where trial participants were enrolled. We thus distinguished two groups of non-participants of met inclusion criteria: those seen at trial sites, and those seen elsewhere. If site-level effects were important, we would expect that trial participants would be similar to the first group but different from the second group.

We used VHA utilization files to identify the demographic characteristics of the non-participant cohort, including age, gender, race, and veteran service-connected disability status. We used diagnosis codes in the hospital discharge and outpatient encounter files to identify psychiatric and medical co-morbidities in both trial participants and non-participants.

\subsection{Cost and utilization data sources}

We obtained information from the VHA Decision Support System on the cost and utilization of hospital, residential care, outpatient services, and pharmacy, including prescriptions for anti-psychotic medications. We considered only care that was provided during the one-year study time frame, excluding the portion of inpatient stays that began before the year or ended after it. We used pharmacy data to estimate patient adherence. Among those who received any antipsychotic medication, we expressed the number of days' supply that was dispensed as a percentage of the days in the study year, and assigned the result to one of the adherence categories described by Gilmer (Gilmer et al., 2004). A dispensed supply that covered less than $50 \%$ of the year was defined as poor adherence, between $50 \%$ and $79 \%$ defined as partial adherence, $80 \%$ to $110 \%$ as adherent; a supply that was sufficient to cover more than $110 \%$ of the study year was defined as over-filled.

We assigned inpatient care to one of three categories: acute psychiatric, acute medical-surgical, and all other, a category that included substance abuse treatment, nursing home, and residential care. Costs were adjusted for inflation and expressed as 2009 U.S. dollars using the Consumer Price Index for all goods.

\subsection{Statistical methods}

We compared trial participants to three other groups: (1) those who met the key inclusion criterion at study sites but were not in the study, (2) those who met this criterion at non-study sites, (3) other VHA users with schizophrenia. Group differences in discrete variables (proportions) were compared with logistic regression, or if there were multiple categories, multinomial logistic regression. Multivariate models were used to minimize the number of tests and the effect on study-wide Type I error. Group differences in utilization counts, including number of outpatient visits, were evaluated with a count data regression. Variances were found to be over dispersed and so a negative binomial regression was used for count data (Cameron and Trivedi, 1998). Generalized Linear Model (GLM) regressions of health care cost avoid the inappropriate assumption of normal distribution and homoscedastic errors (Manning and Mullahy, 2001). We estimated the Box-Cox transformation to identify the appropriate link function (Box and Cox, 1964) and a modified Park test to identify the appropriate distributional family. We found the log linkage function and gamma distribution were the most appropriate specification.

Trial participants were compared to the three comparison groups with respect to 57 variables on demographics, comorbidities, utilization, and cost. These multiple comparisons substantially increase the probability of a Type I statistical error (concluding groups differed when they did not). For this reason, statistical significance was reported in the text only if $p<.001$. At this level of significance, the study-wide probability of a Type I statistical error is $.056\left[1-(1-.001)^{57}\right]$. 


\section{Results}

There were 369 trial participants. Among the non-trial cohort, $23.3 \%(2330 / 10,000)$ had a VA psychiatric stay in the prior 24 months, the key inclusion criterion for trial participation. Among the nonparticipants who met the inclusion criterion, 29.3\% (682/2330) received their care at one of the trial sites.

The characteristics of these groups are compared in Table 1 . There were few significant differences between trial participants and nonparticipants who were met eligibility criterion. The proportion with other psychiatric conditions and substance disorders were similar. They did differ by race. Trial participants were slightly younger than eligible non-participants ( 51.0 vs. 53.5 years, $\mathrm{p}<.001$ ). They were significantly more likely to be African-American than eligible non-participants ( $45.5 \%$ vs. $35.1 \% \mathrm{p}<.001$ ). This was partly due to site-level differences in race. African-Americans made up $38.0 \%$ of eligible non-participants at study sites, and $33.9 \%$ of eligible non-participants at other sites.

Trial participants had more co-morbidities than non-participants without a recent psychiatric hospitalization. Trial participants were more likely to have psychiatric conditions in addition to schizophrenia (81.0\% compared $51.3 \%, \mathrm{p}<.001)$. They were more likely to have depression, bipolar disorder, and Post Traumatic Stress Disorder (PTSD). Substance abuse disorders were diagnosed in $46.3 \%$ of trial participants, compared to $13.9 \%$ of non-participants without a history of hospitalizations $(\mathrm{p}<.001)$. Trial participants were also significantly older and more likely to be single, African-American, or have a diagnosis of hepatitis $\mathrm{C}$.
Health care utilization of the groups during the study year is contrasted in Table 2 . The study period was retrospective: it was the year prior to randomization of trial participants, and the year prior to application of trial enrollment criteria for the comparison cohort. Trial participants had an average of 1.5 psychiatric stays in the study year; the non-participants who did not meet the trial inclusion criterion had, by definition, none. Trial participants had significantly more outpatient visits than the non-participants who did not meet the inclusion criterion, including significantly more individual counseling visits ( 18.3 vs. 8.6, $\mathrm{p}<.001$ ), group therapy visits (10.3 vs. 4.5, $\mathrm{p}<.001$ ), vocational rehabilitation visits (1.6 vs. $0.9, \mathrm{p}<.001$ ), and psychiatric contacts by telephone ( 0.6 vs. $0.3, \mathrm{p}<.001)$. There were fewer differences in utilization between trial participants and nonparticipants who met inclusion criterion, but participants had significantly more group encounters and significantly fewer telephone encounters with psychiatric providers.

Trial participants received slightly more inpatient psychiatric care than non-participants who met the hospitalization inclusion criterion and were treated at sites where the trial did not take place. Trial participants had more acute psychiatric stays (1.5 vs. 1.2 stays, $\mathrm{p}<.001)$ and more days of psychiatric stay (23.3 vs. 17.1 stays, $\mathrm{p}<.001)$. This result may be due to site-level differences in practice, as the number days of psychiatric stay did not differ between study participants and eligible non-participants who received care at study sites. Trial participants were significantly less likely to have had a medical-surgical hospitalization in the study year than non-participants who met the inclusion criterion (8.2\% vs. $19.2 \%, \mathrm{p}<.001)$.

Table 1

Demographics and co-morbidities of CSP 555 trial and non-trial patients.

\begin{tabular}{|c|c|c|c|c|}
\hline Characteristic & $\begin{array}{l}\text { CSP } 555 \text { trial participants } \\
\mathrm{n}=369\end{array}$ & $\begin{array}{l}\text { Met inclusion criterion } \\
\text { at site } n=682\end{array}$ & $\begin{array}{l}\text { Met inclusion criterion } \\
\text { at non-site } n=1648\end{array}$ & $\begin{array}{l}\text { Did not meet inclusion } \\
\text { criterion } n=7670\end{array}$ \\
\hline Age, Mean (SD) & $51.0(9.3)$ & $53.9(10.5)^{*}$ & $53.4(11.3)^{*}$ & $57.2(11.4)^{*}$ \\
\hline Male (percent) & 91.6 & 93.5 & 93.3 & 93.6 \\
\hline \multicolumn{5}{|l|}{ Race/ethnicity (percent in each category) } \\
\hline White & 45.8 & $53.8 \dagger$ & $56.1^{*}$ & $55.5^{*}$ \\
\hline Black & 45.5 & $38.0 \dagger$ & $33.9^{*}$ & $28.5^{*}$ \\
\hline Hispanic & 5.7 & 5.0 & 7.4 & $8.5 \dagger$ \\
\hline Asian/American Indian & 2.7 & 1.6 & 1.2 & 1.7 \\
\hline Unknown & 0.3 & $1.6 \dagger$ & $1.5^{*}$ & $5.7^{*}$ \\
\hline Single/never married (percent) & 85.6 & 82.7 & $80.8 \dagger$ & $70.3^{*}$ \\
\hline \multicolumn{5}{|c|}{ Number of psychiatric co-morbidities (percent in each category) } \\
\hline None & 19.0 & 21.4 & 20.1 & $48.7^{*}$ \\
\hline 1 & 18.2 & 18.5 & 19.5 & 22.1 \\
\hline 2 & 20.6 & 16.7 & 20.1 & 16.8 \\
\hline $3+$ & 42.3 & 43.4 & 40.3 & $12.4^{*}$ \\
\hline Depression (percent) & 38.8 & 35.9 & 35.7 & $19.3^{*}$ \\
\hline Psychoses (percent) & 99.5 & 98.7 & 97.9 & $94.5^{*}$ \\
\hline Antisocial personality disorder (percent) & 4.9 & 5.3 & 3.6 & $0.4^{*}$ \\
\hline Borderline personality (percent) & 3.0 & 5.4 & 3.0 & $0.4^{*}$ \\
\hline Bipolar (percent) & 23.6 & 24.2 & 21.5 & $8.2^{*}$ \\
\hline Post traumatic stress disorder (percent) & 17.1 & 18.2 & 17.1 & $11.6^{*}$ \\
\hline Other non-psychotic disorder (percent) & 52.6 & 54.5 & 54.2 & $32.6^{*}$ \\
\hline Other psychosis (percent) & 25.2 & 23.5 & $20.3 \dagger$ & $7.7^{*}$ \\
\hline Other personality disorder (percent) & 11.7 & 11.6 & 10.1 & $2.1^{*}$ \\
\hline Substance abuse disorder (percent) & 46.3 & 44.7 & 41.4 & $13.9^{*}$ \\
\hline Alcohol dependency/abuse (percent) & 37.4 & 34.6 & 32.7 & $9.7^{*}$ \\
\hline Drug dependency/abuse (percent) & 30.1 & 31.7 & 27.5 & $7.7^{*}$ \\
\hline \multicolumn{5}{|c|}{ Number of medical co-morbidities (percent in each category) } \\
\hline None & 21.3 & 20.3 & 21.6 & $26.1 \dagger$ \\
\hline 1 & 25.6 & 23.3 & 21.7 & 23.8 \\
\hline 2 & 21.5 & 19.7 & 21.6 & 22.1 \\
\hline $3+$ & 31.6 & 36.6 & 35.1 & 27.9 \\
\hline AIDS/HIV (percent) & 1.1 & 1.2 & 1.2 & 0.7 \\
\hline Congestive heart failure (percent) & 2.2 & 4 & 3.3 & 3.0 \\
\hline Chronic obstructive pulmonary disease & 13.3 & 16.6 & $17.6 \dagger$ & 12.5 \\
\hline Diabetes (percent) & 20.6 & 24.3 & 24.3 & 24.0 \\
\hline Hepatitis C (percent) & 13.8 & 13.6 & 11.3 & $6.8^{*}$ \\
\hline Ischemic heart disease (percent) & 6.2 & 9.4 & $9.9 \dagger$ & 9.1 \\
\hline Service connected disability (percent) & 50.1 & $56.5 \dagger$ & $56.8 \dagger$ & $60.1^{*}$ \\
\hline
\end{tabular}

Significantly different from trial participants ${ }^{*} \mathrm{p}<.01 ; \dagger \mathrm{p}<.05$. 
Table 2

Utilization and outpatient anti-psychotic medication for CSP 555 trial and non-trial patients.

\begin{tabular}{|c|c|c|c|c|}
\hline Type of utilization & $\begin{array}{l}\text { CSP } 555 \text { trial participants } \\
\mathrm{n}=369\end{array}$ & $\begin{array}{l}\text { Met inclusion criterion } \\
\text { at site } n=682\end{array}$ & $\begin{array}{l}\text { Met inclusion criterion } \\
\text { at non-site } n=1648\end{array}$ & $\begin{array}{l}\text { Did not meet inclusion } \\
\text { criterion } \mathrm{n}=7670\end{array}$ \\
\hline All inpatient stays, Mean (SD) & $1.9(1.7)$ & $2.0(2.4)$ & $1.7(1.9)$ & $0.2(0.7)^{*}$ \\
\hline \multicolumn{5}{|l|}{ Acute psychiatric hospital stays per person } \\
\hline Number of acute psychiatric stays, Mean (SD) & $1.5(1.3)$ & $1.4(1.9)$ & $1.2(1.4)^{*}$ & - \\
\hline \multicolumn{5}{|l|}{ Number of acute psychiatric stays, $\%$} \\
\hline 0 & 18.4 & $31.2^{*}$ & $33.1^{*}$ & 100.0 \\
\hline 1 & 45.0 & $36.2^{*}$ & 42.0 & - \\
\hline 2 & 20.6 & $15.5 \dagger$ & $13.5^{*}$ & - \\
\hline $3+$ & 16.0 & 17.0 & $11.4 \dagger$ & - \\
\hline Total days in acute psychiatric stay, Mean (SD) & $23.3(44.0)$ & $22.0(43.0)$ & $17.1(37.5)^{*}$ & - \\
\hline \multicolumn{5}{|l|}{ Acute medical/surgical hospital stays per person } \\
\hline At least one acute medical/surgical stay, \% & 9.2 & $19.2^{*}$ & $19.2^{*}$ & 9.3 \\
\hline $\begin{array}{l}\text { Total days in acute medical/surgical stay, } \\
\text { Mean (SD) }\end{array}$ & $0.4(1.7)$ & $1.5(6.1)^{*}$ & $1.7(5.4)^{*}$ & $0.8(5.0)^{*}$ \\
\hline \multicolumn{5}{|l|}{ Other hospital stays per person } \\
\hline At least one other inpatient stay, \% & 19.0 & 16.0 & $14.0 \dagger$ & $4.0^{*}$ \\
\hline Total days in other inpatient stay, Mean (SD) & $12.9(42.2)$ & $14.3(51.2)$ & $11.4(43.9) \dagger$ & $4.3(33.3)^{*}$ \\
\hline All outpatient visits, Mean (SD) & $53.2(61.1)$ & $55.7(61.3)$ & $53.7(61.9)$ & $34.2(48.5)^{*}$ \\
\hline Individual psychiatry & $18.3(23.5)$ & $20.6(28.0)$ & $18.4(25.9)$ & $8.6(17.2)^{*}$ \\
\hline Group psychiatry & $10.3(28.6)$ & $7.0(20.7)^{*}$ & $7.1(25.4)^{*}$ & $4.5(22.1)^{*}$ \\
\hline Vocational rehabilitation & $1.6(10.5)$ & $1.8(13.1)$ & $1.4(10.2) \dagger$ & $0.9(10.4)^{*}$ \\
\hline Telephone psychiatry & $0.6(2.2)$ & $1.0(3.3)^{*}$ & $1.0(3.3)^{*}$ & $0.3(1.8)^{*}$ \\
\hline Other psychiatry & $1.0(1.9)$ & $2.3(14.1)^{*}$ & $2.3(8.8)^{*}$ & $1.4(8.5)^{*}$ \\
\hline Medical/surgical & $8.6(9.4)$ & $9.1(9.4)$ & $9.4(10.4)$ & $7.7(9.3)$ \\
\hline Other ambulatory care & $12.8(19.5)$ & $14.0(16.6)$ & $14.1(20.5)$ & $10.7(16.5)^{*}$ \\
\hline
\end{tabular}

Significantly different from trial participants $* \mathrm{p}<.01 ; \dagger \mathrm{p}<.05$

Anti-psychotic medication had been dispensed to most (87.0\%) trial participants. This was significantly more than the $76.8 \%$ of nonparticipants who received anti-psychotic medications during the comparable time period ( $\mathrm{p}<.001$ ). The types of anti-psychotic medications and the administrative measure of medication adherence among those who received any anti-psychotics during the year are presented in the lower portion of Table 3 . These statistics exclude 28 individuals in a long-term inpatient episode (one of $>270$ days). Trial participants were significantly more likely to have received atypical anti-psychotic medications then non-participants who did not meet inclusion criterion.

Trial participants were significantly more likely to receive an atypical medication than eligible non-participants at other sites. Again, there was evidence of some site-level differences in care; there was no significant difference between trial participants and eligible non-participants who received care at the sites where the trial took place.

Among those who received anti-psychotic medications, trial participants were significantly more likely to be not adherent (a medication possession ratio of less than $50 \%$ ) and significantly more likely to be an over fillers (with a possession ration of more than $110 \%$ ) than those who did not meet the trial inclusion criterion. There were no-significant differences in adherence between trial participants and eligible nonparticipants.

The 10,000 individuals in the comparison cohort incurred an average of $\$ 18,754$ annual health care costs, including $23.3 \%$ for acute inpatient psychiatric care and $7.2 \%$ for anti-psychotic medications. Mean health care costs incurred by study groups during the study year are presented in Table 4. Trial participants incurred significantly more cost than non-participants who had no history of hospitalization in the prior 24 months ( $\$ 42,563$ vs. $\$ 12,270, \mathrm{p}<.001$ ). This difference was attributable to significantly greater hospital cost $(\$ 29,882$ vs. $\$ 4200 \mathrm{p}<.001)$, greater costs of outpatient care $(\$ 11,057$ vs. $\$ 6824$ $\mathrm{p}<.001$ ), and greater cost for anti-psychotic medications (\$1624 vs. $\$ 1247 \mathrm{p}<.01$ ). There were no significant differences in the total cost of care incurred by trial participants and eligible non-participants. Trial participants incurred a mean of $\$ 942$ cost for acute medical hospital

Table 3

Outpatient prescription medication for trial and non-trial patients.

\begin{tabular}{|c|c|c|c|c|}
\hline Description & $\begin{array}{l}\text { CSP } 555 \text { trial participants } \\
\mathrm{n}=369\end{array}$ & $\begin{array}{l}\text { Met inclusion criterion } \\
\text { at site } n=682\end{array}$ & $\begin{array}{l}\text { Met inclusion criterion } \\
\text { at non-site } n=1648\end{array}$ & $\begin{array}{l}\text { Did not meet inclusion } \\
\text { criterion } \mathrm{n}=7670\end{array}$ \\
\hline Excluded because $>270$ days of stay & 2 & 6 & 9 & 11 \\
\hline Non-institutionalized patients & 367 & 676 & 1639 & 7659 \\
\hline \multicolumn{5}{|l|}{$\begin{array}{l}\text { Non-institutionalized patients who } \\
\text { received anti-psychotic medication }\end{array}$} \\
\hline Number & 319 & 567 & 1369 & 5879 \\
\hline Percent & 87.0 & 84.0 & 83.6 & $76.8^{*}$ \\
\hline \multicolumn{5}{|l|}{ Type of anti-psychotic medication, $+\%$} \\
\hline Conventional only & 4.7 & 7.6 & $8.5 \dagger$ & $15.8^{*}$ \\
\hline Atypical only & 80.3 & 75.3 & $69.8^{*}$ & $72.9^{*}$ \\
\hline Both conventional and atypical & 15.0 & 17.1 & $21.7^{*}$ & $11.3 \dagger$ \\
\hline Received depot medication, $\ddagger \%$ & 8.8 & $17.3^{*}$ & $17.2^{*}$ & 6.9 \\
\hline \multicolumn{5}{|l|}{ Adherence, $\$ \%$} \\
\hline Not adherent & 28.8 & 28.2 & 25.4 & $21.4^{*}$ \\
\hline Partially adherent & 22.3 & 19.0 & 19.7 & $18.3^{*}$ \\
\hline Adherent & 21.3 & 23.1 & 24.1 & 37.9 \\
\hline Over fillers & 27.6 & 29.6 & 30.8 & $22.4 \dagger$ \\
\hline
\end{tabular}

Significantly different from trial participants ${ }^{*} \mathrm{p}<.01 ; \dagger \mathrm{p}<.05$.

$\ddagger$ Among those who received an anti-psychotic medication who were not institutionalized (less than 270 days of stay). 
Table 4

Average costs for trial and non-trial patients (2009 U.S. dollars).

\begin{tabular}{|c|c|c|c|c|}
\hline Type of cost & $\begin{array}{l}\text { CSP } 555 \text { trial participants } \\
\mathrm{n}=369\end{array}$ & $\begin{array}{l}\text { Met inclusion criterion } \\
\text { at site } n=682\end{array}$ & $\begin{array}{l}\text { Met inclusion criterion } \\
\text { at non-site } n=1648\end{array}$ & $\begin{array}{l}\text { Did not meet inclusion } \\
\text { criterion } n=7670\end{array}$ \\
\hline \multicolumn{5}{|l|}{ Inpatient } \\
\hline Acute psychiatric hospital stays & 23,087 & 21,101 & $17,736 \dagger$ & - \\
\hline Acute medical/surgical hospital stays & 942 & $2999 *$ & $3301^{*}$ & $1914 \dagger$ \\
\hline Other hospital stays & 5852 & 6520 & 4900 & $2287 \dagger$ \\
\hline Total inpatient & 29,882 & 30,620 & 25,936 & $4200^{*}$ \\
\hline \multicolumn{5}{|l|}{ Outpatient } \\
\hline Individual psychiatry & 4373 & 5104 & 4232 & $1891^{*}$ \\
\hline Group psychiatry & 1333 & 1105 & 893 & $563^{*}$ \\
\hline Vocational rehabilitation & 360 & 283 & 262 & 151 \\
\hline Telephone psychiatry & 84 & 108 & 111 & $39 \dagger$ \\
\hline Other psychiatry & 78 & 206 & 226 & 81 \\
\hline Medical/surgical & 2929 & 2820 & 2646 & $2023^{*}$ \\
\hline Other ambulatory care & 1900 & 2316 & 2439 & 2076 \\
\hline Total outpatient & 11,057 & 11,942 & 10,807 & $6824^{*}$ \\
\hline \multicolumn{5}{|l|}{ Anti-psychotic medication } \\
\hline Conventional only & 31 & 38 & 46 & 48 \\
\hline Atypical only & 1593 & 1714 & 1566 & $1199^{*}$ \\
\hline Total anti-psychotic medications & 1624 & 1753 & 1612 & $1247^{*}$ \\
\hline Total, average cost per patient & 42,563 & 44,315 & 38,356 & $12,270^{*}$ \\
\hline
\end{tabular}

Significantly different from trial participants $* \mathrm{p}<.01 ; \dagger \mathrm{p}<.05$.

says, significantly less than the $\$ 2999$ incurred by eligible nonparticipants at study sites $(\mathrm{p}<.01)$ and the $\$ 3301$ incurred by eligible non-participants at other sites $(\mathrm{p}<.001)$.

\section{Discussion}

The key trial inclusion criterion, psychiatric hospitalization in the prior 24 months, succeeded in identifying the more seriously ill, more costly, and less medication adherent patients with schizophrenia and schizoaffective disorder, the individuals most likely to benefit from injectable risperidone. Trial participants were more likely to have psychiatric and substance abuse comorbidities recorded in administrative data than non-participants who did not meet the inclusion criterion, including depression, bipolar disorder, and Post Traumatic Stress Disorder. Trial participants incurred a mean of $\$ 42,563$ in annual health care cost, more than 3 times the $\$ 12,270$ incurred by non-participants who did not meet this inclusion criterion.

Trial participants had greater problems with medication adherence. Among ambulatory patients with schizophrenia who received at least one prescription for an anti-psychotic medication, just $21.3 \%$ of trial participants had good adherence, significantly less than the $37.9 \%$ adherence among non-participants who did not meet the inclusion criterion. This poor adherence involved insufficient medication and also excessive supply. Both under use and oversupply of medication are associated with worse outcomes (Valenstein et al., 2002; Gilmer et al., 2004; Eaddy et al., 2005).

Trial participants appeared to be representative of a large but distinctive segment of patients with schizophrenia or schizoaffective disorder. The trial inclusion criterion was met by $23.3 \%$ of a random selection of VHA patients with these illnesses. There were few observable differences between trial participants and non-participants who met the trial inclusion criterion, suggesting that the trial findings will be relevant to the broader group of high risk patients.

Other studies have compared participants in schizophrenia trials to non-participants who met enrollment criteria and received care in the same health care setting. A study of psychiatric inpatients found trial participants were younger and had a more recent onset of illness than non-participants (Hofer et al., 2000). A study of patients in community mental health centers found participants were younger and used more services; in trials that included patients with substance use disorders, participants were more likely to be minorities and less likely to have medical comorbidities (Woods et al., 2000). We found similar results in this study. Trial participants were slightly younger, more likely to be African-American, and more likely to have had a recent medical-surgical hospitalization than non-participants who met inclusion criteria. Part of the difference in racial characteristics was attributable to site-level effects. Among VA patients with schizophrenia who met trial inclusion criteria, the proportion that was African-American was greater at trial sites. We did not find that trial participants used more services than non-participants; however, high utilization (recent hospitalization) was the inclusion criterion that was applied to both groups.

This study has limitations imposed by its reliance on administrative data. The accuracy and completeness of diagnostic coding is uncertain, especially among patients with little health care utilization. Although the trial inclusion criterion would be met by a non-VA hospital stay, we had no information on the psychiatric hospitalizations outside of VHA of non-participants. As a result, we have understated the number of non-participants who would have met the trial inclusion criterion. We lacked information on costs outside the VHA system. Total cost of care is thus understated. Although VHA patients use other providers, those with mental health services conditions are less likely to do so (Petersen et al., 2010).

We determined that individuals with schizophrenia treated in the VHA health care system in the years 2006-2008 incurred a mean of $\$ 18,754$ in annual health care costs, $7.2 \%$ of which was for antipsychotic medications. Although total cost of care is consistent with other studies, VHA has lower medication cost. VHA has negotiated substantial discounts from pharmaceutical suppliers (United States Congress. Congressional Budget Office, 2005).

One study found VHA medication costs to be $40 \%$ less than other U.S. health care sponsors (Render et al., 2003). A study of California Medicaid recipients with schizophrenia found mean annual costs of $\$ 14,103$ in $2001,20.2 \%$ of which was anti-psychotic medication (Duggan, 2005). A multi-site observational study of schizophrenia patients in VHA, community mental health centers, and community and state hospitals found mean annual costs of $\$ 16,098$ in the period 1997-2003, with $23.4 \%$ of these costs attributed to anti-psychotics (Zhu et al., 2008).

The VA trial of LAI risperidone enrolled patients with poor medication adherence, high rates of psychiatric hospitalization, and significant co-morbidities, a group that might best be able to benefit from the expense of a long-acting second generation anti-psychotic medication. Trial participants appeared to be representative of the $23.3 \%$ of patients who had a psychiatric hospitalization in the previous 24 months, a large high-risk population. We believe that this is one of 
the first studies to compare trial participants to patients with a similar diagnosis, and to describe the population of a national health care system whose care may be guided by trial findings.

\section{Role of funding source}

This work was supported by the Veterans Affairs Cooperative Studies Program (Cooperative Study 555); and an unrestricted grant and Risperdal Consta ${ }^{\circledR}$ provided by Ortho-McNeil Janssen Scientific Affairs, LLC. Janssen had no role in study design; in the collection, analysis and interpretation of data; in the writing of the report; and in the decision to submit the paper for publication.

\section{Contributors}

Author Barnett designed the cohort comparison study, supervised analyses, and wrote the manuscript. Author Yang analyzed data set and conducted statistical analyses. Author Rosenheck wrote the protocol for the clinical trial, reviewed literature, and contributed to the text and analysis. All authors contributed to and have approved the final manuscript.

\section{Conflicts of interest}

Robert Rosenheck has received research support from Eli Lilly, Janssen Pharmaceutica, Astra-Zeneca and Wyeth Pharmaceuticals. He has been a consultant to GlaxoSmithKline, Bristol Myers Squibb, Organon and Janssen Pharmaceutica. He provided expert testimony for the plaintiffs in UFCW Local 1776 and Participating Employers Health and Welfare Fund, et al. v. Eli Lilly and Company; for the respondent in Eli Lilly Canada Inc vs. Novapharm Ltd and Minister of Health, and for the Patent Medicines Prices Review Board. Canada, in the matter of Janssen Ortho Inc. and "Risperdal Consta." Paul Barnett and Jennifer Yang have no competing interests.

\section{Acknowledgements}

The CSP 555 Research Group consisted of:

Executive Committee: R. Rosenheck (chair), P. Barnett, P. Hicks, J. Krystal, R. Lew, M. Liang, L. Suvalsky, J. Vertrees

VA Cooperative Studies Program Coordinating Center, VA Boston Healthcare System, Boston, MA-L. Fiore (Director); M. Brophy, (Acting Director), M. Liang (Study Director), D. Valley (Project Manager), G. Muldoon (Associate Center Director for Operations); M. Andino (Chief, Administration); R. Lew and S. Thwin (Biostatisticians); C. Neal (Research Assistant);

VA Cooperative Studies Program Clinical Research Pharmacy Coordinating Center, Albuquerque, NM-M. Sather (Director), J. Vertrees (Pharmacist), D. Conner (Project Manager), D. Krueger and C. Haakenson (Monitors);

VA Health Economics Resource Center-P. Barnett (Economist);

VA Office of Research and Development, Clinical Science Research and Development, Washington, DC-T. O'Leary (Deputy CRADO and Director, CSR\&D), G. Huang (Cooperative Studies Program Deputy Director);

Study Chair's Office-VA Connecticut Healthcare System, West Haven, CT-R. Rosenheck and J. Krystal (Study Cochairs), B. Fuhr (National Coordinator).

The following investigators are listed by study site: L. Albers, Long Beach VA Medical Center, Long Beach, CA; K. Arlinghaus, Houston VA Medical Center, Houston, TX, J. Canive, Albuquerque VA Medical Center, Albuquerque, NM, S. Caroff, Philadelphia VA Medical Center, Philadelphia, PA; L. Davis, Tuscaloosa VA Medical Center, Tuscaloosa, AL; C. DeSouza, Kansas City VA Medical Center, Kansas City, MO; R. Douyon, Miami VA Medical Center, Miami, FL; D. D'Souza, VA Connecticut Healthcare System, West Haven, CT; P. Fore, Jesse Brown VA Medical Center, Chicago, IL; S. Gowda, Augusta VA Medical Center, Augusta, GA; J. Grabowski, John Dingell VA Medical Center Detroit, MI; P. Hicks, VA Central Texas Healthcare System, Waco,TX; J. Hoblyn, Palo Alto VA Medical Center, Palo Alto, CA; E. Konicki, Louis Stokes Cleveland VA Medical Center Cleveland, OH; E. Monnelly, Boston VA Healthcare System, Boston, MA; L. Suvalsky, Minneapolis VA Medical Center, Minneapolis, MN; A.Tapp, VA Puget Sound Healthcare System, Seattle, WA; A. Wolkin, VA New York Harbor Healthcare System, New York, NY, F. Petty, VA Nebraska-Western Iowa Health Care System, Omaha, NE.

\section{References}

Bai, Y.M., Ting Chen, T. Chen, JY., Chang W.H, Wu, B., Hung C.H., Kuo Lin, W., 2007. Equivalent switching dose from oral risperidone to risperidone long-acting injection: a 48-week randomized, prospective, single-blind pharmacokinetic study. J. Clin. Psychiatry 68, 1218-1225.
Box, G.E.P., Cox, D.R., 1964. An analysis of transformations. J. Royal Stat. Soc. Series B (Method.) 26, 211-252.

Cameron, A.C., Trivedi, P.K., 1998. Regression Analysis of Count Data. Cambridge University Press.

Chue, P., Eerdekens, M., Augustyns, I., Lachaux, B., Molcan, P., Eriksson, L., Pretorius, H., David, A.S., 2005a. Comparative efficacy and safety of long-acting risperidone and risperidone oral tablets. Eur. Neuropsychopharmacol. 15, 111-117.

Chue, P.S., Heeg, B., Buskens, E., van Hout, B.A., 2005b. Modelling the impact of compliance on the costs and effects of long-acting risperidone in Canada. Pharmacoeconomics 23 (Suppl 1), 62-74.

Duggan, M., 2005. Do new prescription drugs pay for themselves? The case of secondgeneration antipsychotics. J. Health Econ. 24, 1-31.

Eaddy, M., Grogg, A., Locklear, J., 2005. Assessment of compliance with antipsychotic treatment and resource utilization in a medicaid population. Clin. Ther. 27, 263-272.

Edwards, N.C., Locklear, J.C., Rupnow, M.F., Diamond, R.J., 2005. Cost effectiveness of long-acting risperidone injection versus alternative antipsychotic agents in patients with schizophrenia in the USA. Pharmacoeconomics 23 (Suppl 1), 75-89.

Fleischhacker, W.W., Eerdekens, M., Karcher, K., Remington, G., Llorca, P.M., Chrzanowski, W., Martin, S., Gefvert, O., 2003. Treatment of schizophrenia with long-acting injectable risperidone: a 12-month open-label trial of the first longacting second-generation antipsychotic. J. Clin. Psychiatry 64, 1250-1257.

Gilbody, S., Wahlbeck, K., Adams, C., 2002. Randomized controlled trials in schizophrenia: a critical perspective on the literature. Acta Psychiatr. Scand. 105, 243-251.

Gilmer, T.P., Dolder, C.R., Lacro, J.P., Folsom, D.P., Lindamer, L., Garcia, P., Jeste, D.V., 2004. Adherence to treatment with antipsychotic medication and health care costs among Medicaid beneficiaries with schizophrenia. Am. J. Psychiatry 161, 692-699.

Hofer, A, Hummer, M., Huber, R, Kurz, M., Walch, T, Fleischhacker, W.W., 2000. Selection bias in clinical trials with antipsychotics. J. Clin. Psychopharmacol. 20, 699-702.

Johnsen, E., Jorgensen, H.A., 2008. Effectiveness of second generation antipsychotics: a systematic review of randomized trials. BMC Psychiatry 8, 31 .

Kane, J.M., Eerdekens, M., Lindenmayer, J.P., Keith, S.J., Lesem, M., Karcher, K., 2003. Long-acting injectable risperidone: efficacy and safety of the first long-acting atypical antipsychotic. Am. J. Psychiatry 160, 1125-1132.

Keks, N.A., Ingham, M., Khan, A., Karcher, K., 2007. Long-acting injectable risperidone v. olanzapine tablets for schizophrenia or schizoaffective disorder. Randomised, controlled, open-label study. Br. J. Psychiatry 191, 131-139.

Lindenmayer, J.P., Eerdekens, E., Berry, S.A., Eerdekens, M., 2004. Safety and efficacy of long-acting risperidone in schizophrenia: a 12-week, multicenter, open-label study in stable patients switched from typical and atypical oral antipsychotics. J. Clin. Psychiatry 65, 1084-1089.

Manning, W.G., Mullahy, J., 2001. Estimating log models: to transform or not to transform? J. Health Econ. 20, 461-494.

Moller, H.J., Llorca, P.M., Sacchetti, E., Martin, S.D., Medori, R., Parellada, E., 2005. Efficacy and safety of direct transition to risperidone long-acting injectable in patients treated with various antipsychotic therapies. Int. Clin. Psychopharmacol. 20, 121-130.

Petersen, L.A., Byrne, M.M., Daw, C.N., Hasche, J., Reis, B., Pietz, K., 2010. Relationship between clinical conditions and use of Veterans Affairs health care among Medicare-enrolled veterans. Health Serv. Res. 45, 762-791.

Render, M.L., Nowak, J., Hammond, E.K., Roselle, G., 2003. Methods for estimating and comparing VA outpatient drug benefits with the private sector. Med. Care 41, II61-II69.

Thieda, P., Beard, S., Richter, A., Kane, J., 2003. An economic review of compliance with medication therapy in the treatment of schizophrenia. Psychiatr. Serv. 54, 508-516.

United States Congress. Congressional Budget Office, 2005. Prices for brand-name drugs under selected federal programs. CBO Paper.

Valenstein, M., Copeland, L.A., Blow, F.C., McCarthy, J.F., Zeber, J.E., Gillon, L., Bingham, C.R., Stavenger, T., 2002. Pharmacy data identify poorly adherent patients with schizophrenia at increased risk for admission. Med. Care 40, 630-639.

Weiden, P.J., Olfson, M., 1995. Cost of relapse in schizophrenia. Schizophr. Bull. 21, 419-429.

Woods, S.W., Ziedonis, D.M., Sernyak, M.J., Diaz, E., Rosenheck, R.A., 2000. Characteristics of participants and nonparticipants in medication trials for treatment of schizophrenia. Psychiatr. Serv. 51, 79-84.

Yang, Y.K., Tarn, Y.H., Wang, T.Y., Liu, C.Y., Laio, Y.C., Chou, Y.H., Lee, S.M., Chen, C.C., 2005. Pharmacoeconomic evaluation of schizophrenia in Taiwan: model comparison of long-acting risperidone versus olanzapine versus depot haloperidol based on estimated costs. Psychiatry Clin. Neurosci. 59, 385-394.

Zhu, B., Ascher-Svanum, H., Faries, D.E., Peng, X., Salkever, D., Slade, E.P., 2008. Costs of treating patients with schizophrenia who have illness-related crisis events. BMC Psychiatry 8, 72 . 